\title{
Synthesis, characterization and cytotoxicity of $\mathrm{Mn}$ (II) and $\mathrm{Cu}(\mathrm{II})$ complexes with $\mathrm{N}$-substituted glycine hydrazone
}

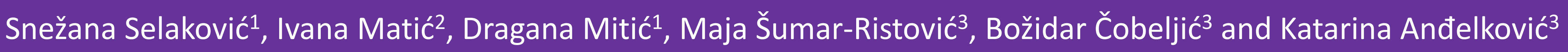 ${ }_{1}^{1}$ nnovation center of the Faculty of Chemistry, University of Belgrade, Studentski trg 12-16, 11000 Belgrade, Serbia ${ }^{2}$ Institute of Oncology and Radiology of Serbia, Pasterova 14, Belgrade, Serbia ${ }^{3}$ Faculty of Chemistry, University of Belgrade, Studentski trg 12-16, 11000 Belgrade, Serbia}

\section{Synthesis:}
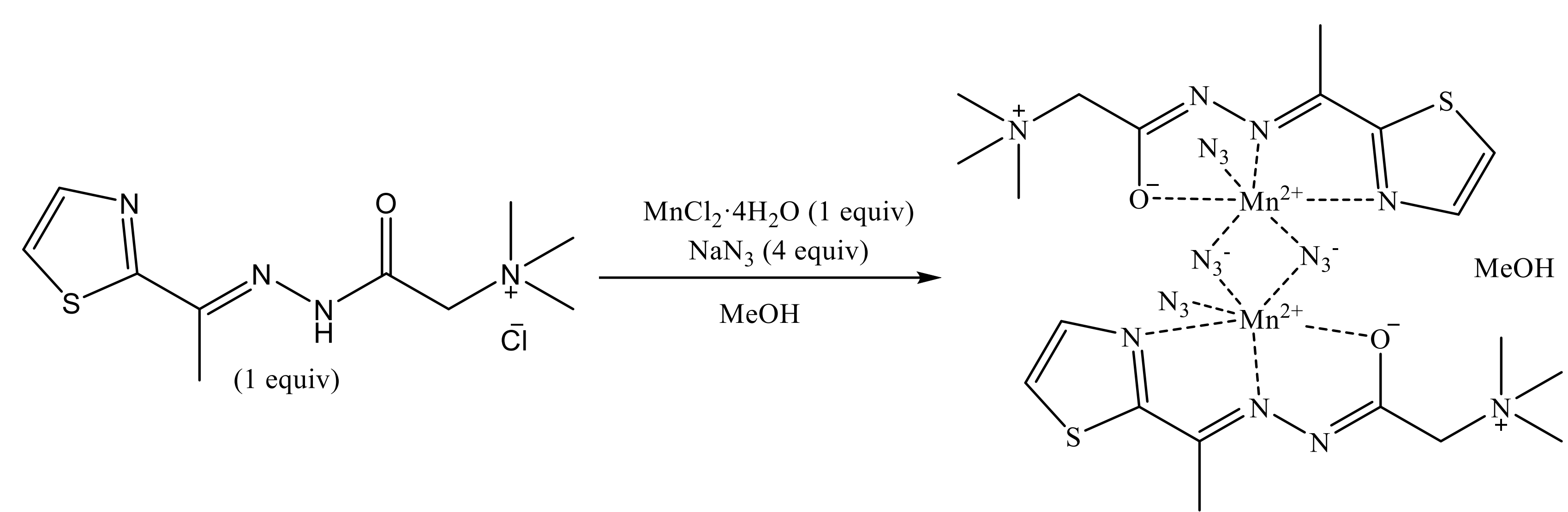

Scheme 1: Synthesis of complex $\left[\mathrm{Mn}_{2} \mathrm{~L}_{2}\left({ }_{\mu-1,1-1} \mathrm{~N}_{3}\right)_{2}\left(\mathrm{~N}_{3}\right)_{2}\right] \mathrm{MeOH}$

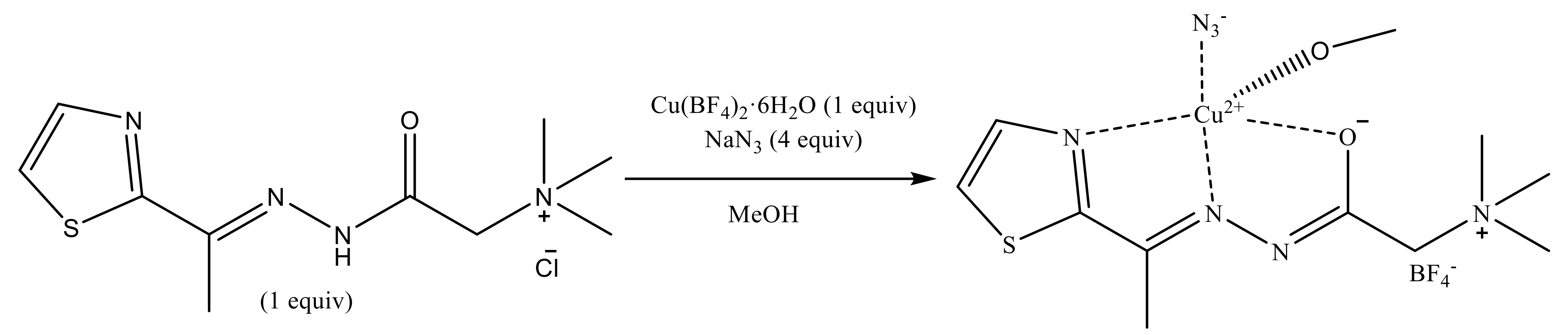

Scheme 2: Synthesis of complex $\left[\mathrm{CuL}\left(\mathrm{N}_{3}\right)(\mathrm{MeOH})\right] \mathrm{BF}_{4}$

\section{Structure:}

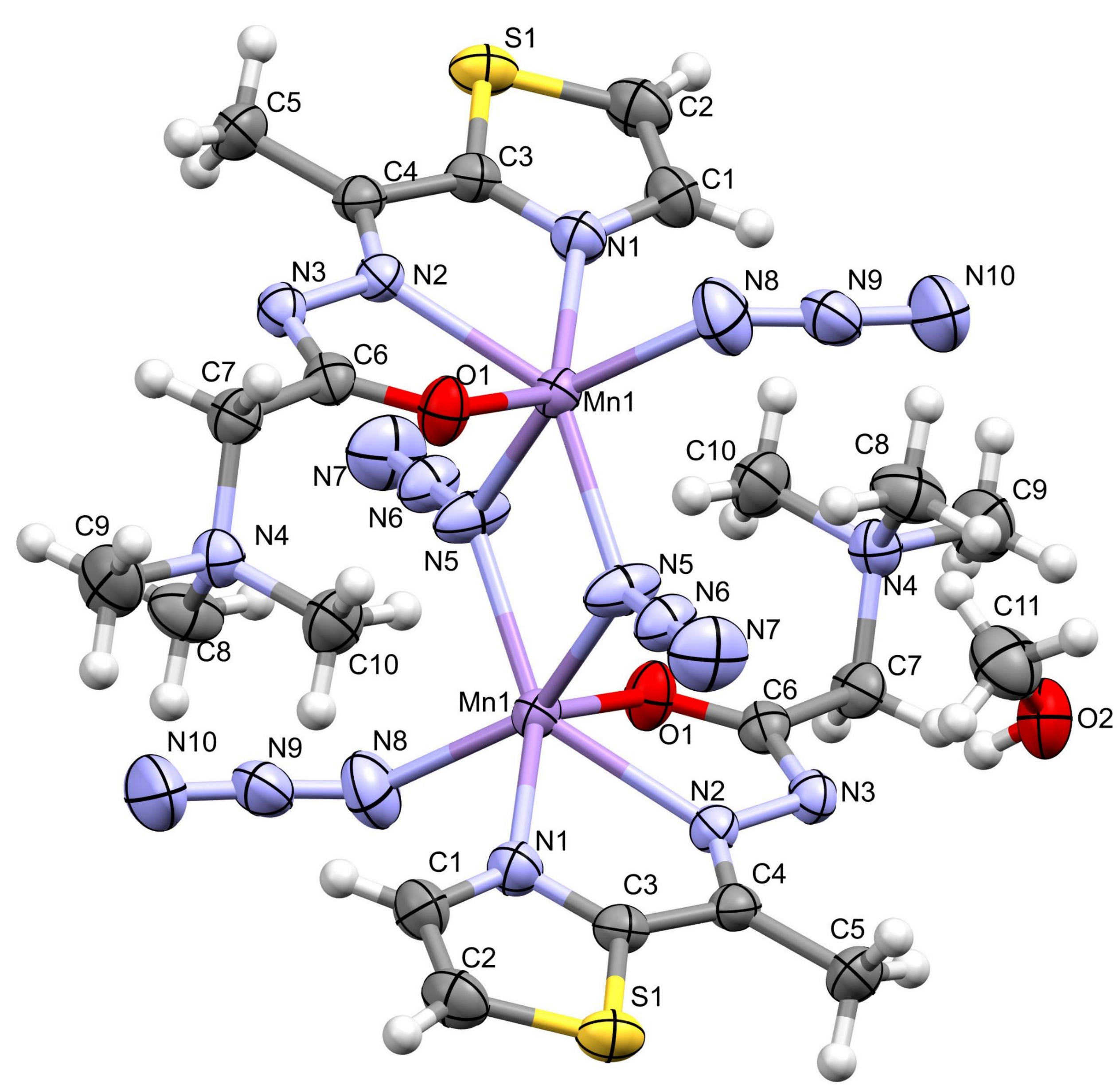

Picture 1: Graphical presentation of the molecular structure of $\left[\mathrm{Mn}_{2} \mathrm{~L}_{2}\left({ }_{\mu-1,1-1} \mathrm{~N}_{3}\right)_{2}\left(\mathrm{~N}_{3}\right)_{2}\right] \mathrm{MeOH}$. Thermal ellipsoids are drawn at the $40 \%$ probability level

Table 1: Selected bond lengths $(\AA)$ and angles $\left({ }^{\circ}\right)$ for complex $\left[\mathrm{Mn}_{2} \mathrm{~L}_{2}\left({ }_{\mu-1,1-} \mathrm{N}_{3}\right)_{2}\left(\mathrm{~N}_{3}\right)_{2}\right] \mathrm{MeOH}$, with esd's in parentheses

\begin{tabular}{cc}
$\mathrm{Mn}(1)-\mathrm{N}(8)$ & $2.112(2)$ \\
$\mathrm{Mn}(1)-\mathrm{O}(1)$ & $2.1879(16)$ \\
$\mathrm{Mn}(1)-\mathrm{N}(5)$ & $2.229(2)$ \\
$\mathrm{Mn}(1)-\mathrm{N}(5)$ & $2.2425(19)$ \\
$\mathrm{Mn}(1)-\mathrm{N}(2)$ & $2.2500(18)$ \\
$\mathrm{Mn}(1)-\mathrm{N}(1)$ & $2.3668(19)$ \\
& \\
$\mathrm{N}(8)-\mathrm{Mn}(1)-\mathrm{O}(1)$ & $98.88(9)$ \\
$\mathrm{N}(8)-\mathrm{Mn}(1)-\mathrm{N}(5)$ & $147.86(10)$ \\
$\mathrm{O}(1)-\mathrm{Mn}(1)-\mathrm{N}(5)$ & $107.66(8)$ \\
$\mathrm{N}(8)-\mathrm{Mn}(1)-\mathrm{N}(2)$ & $121.21(9)$ \\
$\mathrm{O}(1)-\mathrm{Mn}(1)-\mathrm{N}(2)$ & $69.51(6)$ \\
$\mathrm{N}(5)-\mathrm{Mn}(1)-\mathrm{N}(2)$ & $85.67(7)$ \\
$\mathrm{N}(8)-\mathrm{Mn}(1)-\mathrm{N}(1)$ & $86.84(9)$ \\
$\mathrm{O}(1)-\mathrm{Mn}(1)-\mathrm{N}(1)$ & $134.91(7)$ \\
$\mathrm{N}(5)-\mathrm{Mn}(1)-\mathrm{N}(1)$ & $87.04(7)$ \\
$\mathrm{N}(2)-\mathrm{Mn}(1)-\mathrm{N}(1)$ & $69.46(7)$ \\
\hline
\end{tabular}

Structure:

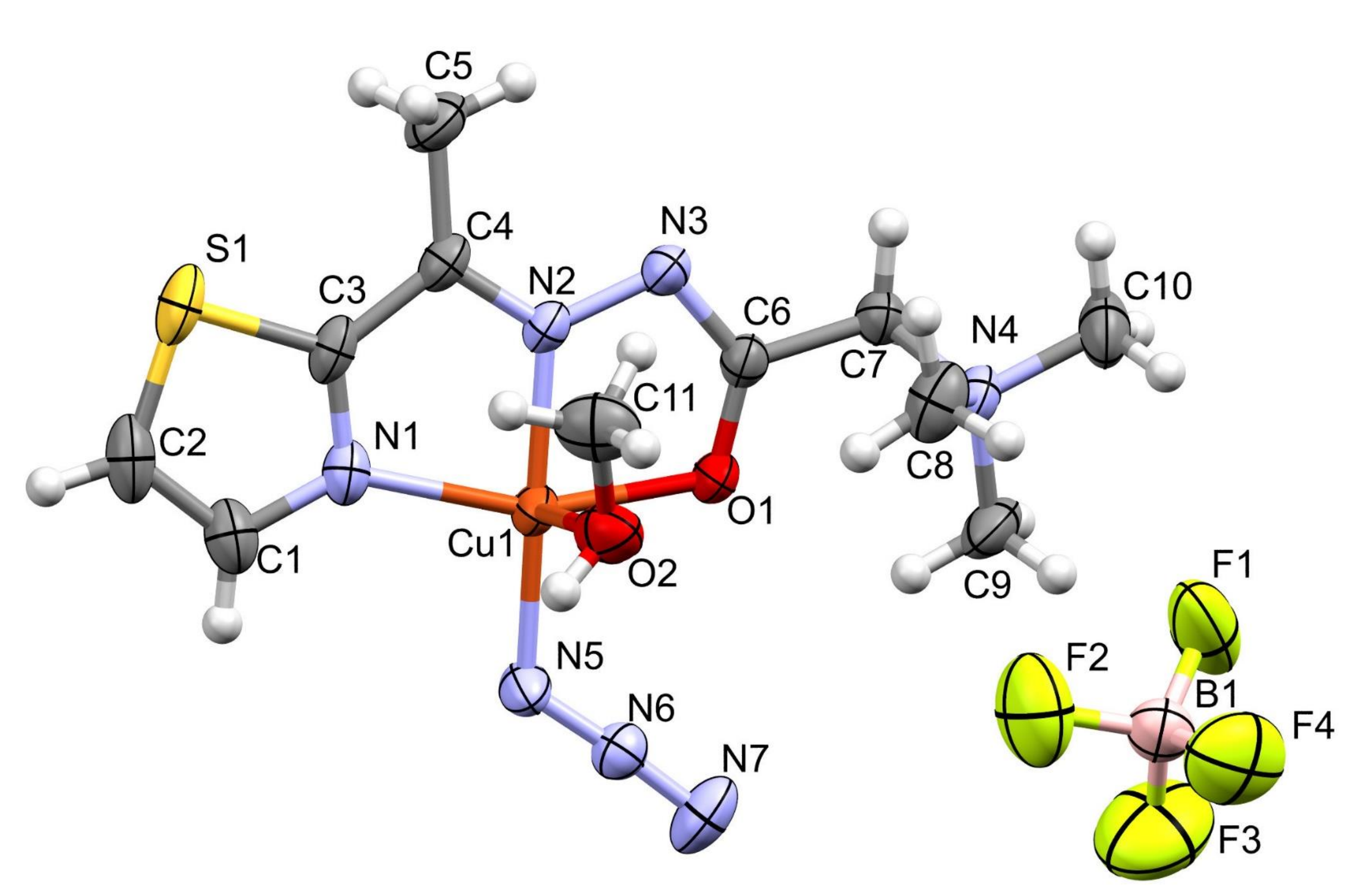

Picture 2: Graphical presentation of the molecular structure of $\left[\mathrm{CuL}\left(\mathrm{N}_{3}\right)(\mathrm{MeOH})\right] \mathrm{BF}_{4}$. Thermal ellipsoids are drawn at the $40 \%$ probability level

Table 2: Selected bond lengths $(\AA)$ and angles $\left({ }^{\circ}\right)$ for complex $\left[\mathrm{CuL}\left(\mathrm{N}_{3}\right)(\mathrm{MeOH})\right] \mathrm{BF}_{4}$, with esd's in parentheses

$\begin{array}{lc}\mathrm{Cu}(1)-N(5) & 1.924(3) \\ \mathrm{Cu}(1)-N(2) & 1.927(2) \\ \mathrm{Cu}(1)-\mathrm{O}(1) & 1.971(2) \\ \mathrm{Cu}(1)-\mathrm{N}(2) & 2.046(3) \\ & \\ & 174.73(12) \\ 5)-\mathrm{Cu}(1)-\mathrm{N}(2) & 98.54(11) \\ 5)-\mathrm{Cu}(1)-\mathrm{O}(1) & 79.27(9) \\ 2)-\mathrm{Cu}(1)-\mathrm{O}(1) & 100.88(11) \\ 5)-\mathrm{Cu}(1)-\mathrm{N}(1) & 80.69(11) \\ 2)-\mathrm{Cu}(1)-\mathrm{N}(1) & 158.98(11)\end{array}$

\section{Cytotoxicity:}
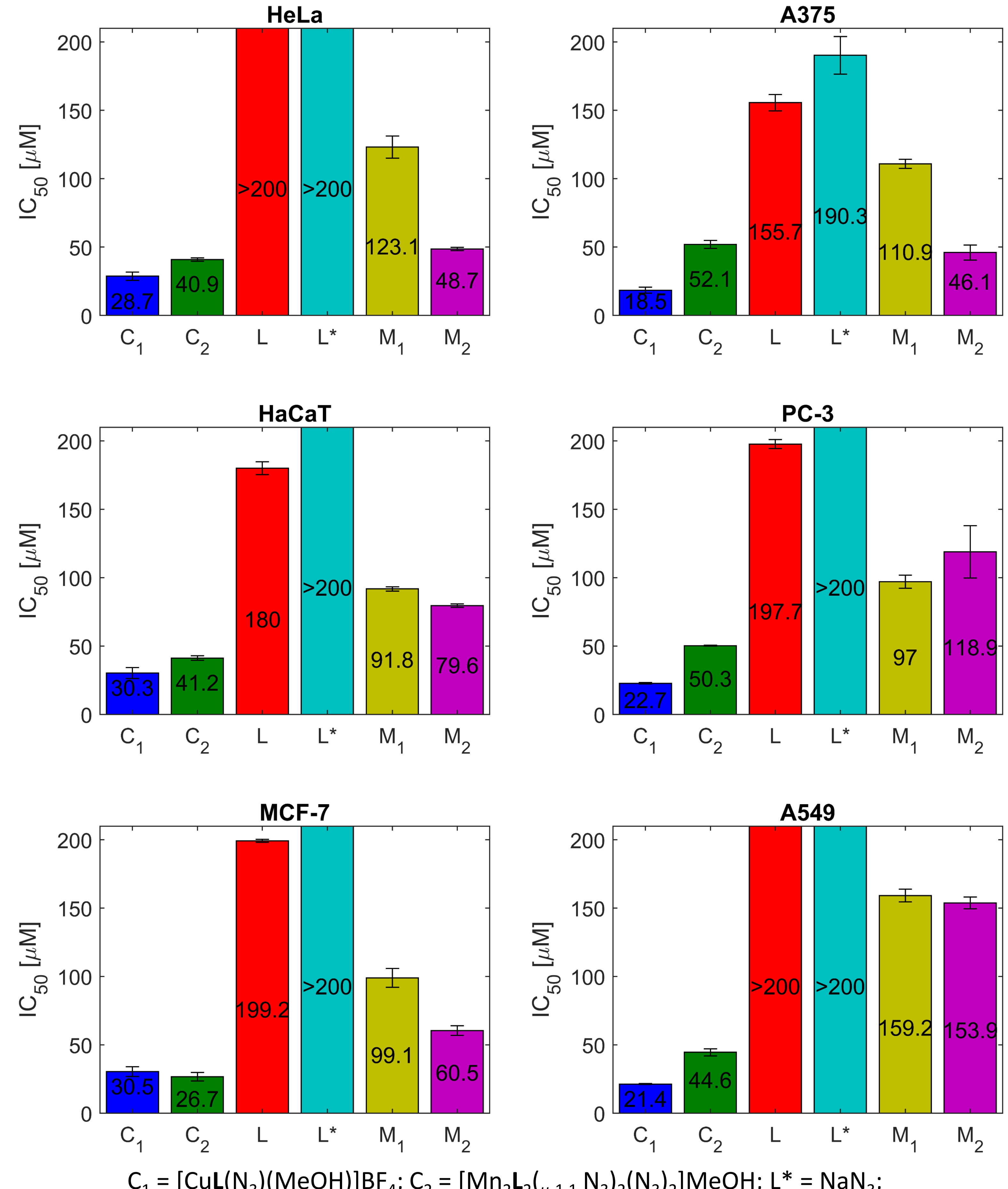

$\mathrm{C}_{1}=\left[\mathrm{CuL}\left(\mathrm{N}_{3}\right)(\mathrm{MeOH})\right] \mathrm{BF}_{4} ; \mathrm{C}_{2}=\left[\mathrm{Mn}_{2} \mathrm{~L}_{2}\left(\mathrm{M}_{\mu-1,1}-\mathrm{N}_{3}\right)_{2}\left(\mathrm{~N}_{3}\right)_{2}\right] \mathrm{MeOH} ; \mathrm{L}^{*}=\mathrm{NaN}_{3}$ $\mathrm{M}_{1}=\mathrm{Cu}\left(\mathrm{BF}_{4}\right)_{2} \cdot 6 \mathrm{H}_{2} \mathrm{O} ; \mathrm{M}_{2}=\mathrm{MnCl}_{2} \cdot 4 \mathrm{H}_{2} \mathrm{O}$

Conclusion: $\mathrm{Mn}(\mathrm{II})$ and $\mathrm{Cu}(\mathrm{II})$ complexes with $\mathrm{N}$-substituted glycine hydrazone ligand were synthesized and characterized. Complexes exerted strong to moderate cytotoxic activities against tested malignant cell lines. $\mathrm{Cu}(\mathrm{II})$ complex showed higher cytotoxic effects on malignant cells when compared to Mn(II) complex, except against MCF7 cells. The both complexes exhibited higher cytotoxicity in comparison with its ligand. 